\title{
24
}

\section{Prospects for Agriculture Under Climate Change and Soil Salinisation}

\author{
Derek Clarke, Attila N. Lázár, Abul Fazal M. Saleh, \\ and Mohammad Jahiruddin
}

\subsection{Agriculture as an Ecosystem Service in Bangladesh}

Agriculture is the largest and most important provisioning ecosystem in the world (Zhang et al. 2007), covering 38 per cent of the global land area (DeClerck et al. 2016). In addition to providing important ecosystem services, agriculture also relies on, is impacted by and alters many other ecosystem services (Fig. 24.1). As the population of the world and

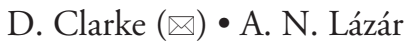

Faculty of Engineering and the Environment and Tyndall Centre for Climate Change Research, University of Southampton, Southampton, UK

\section{A. F. M. Saleh}

Institute of Water and Flood Management, Bangladesh University of Engineering and Technology, Dhaka, Bangladesh

M. Jahiruddin

Department of Soil Science, Bangladesh Agricultural University, Mymensingh, Bangladesh 


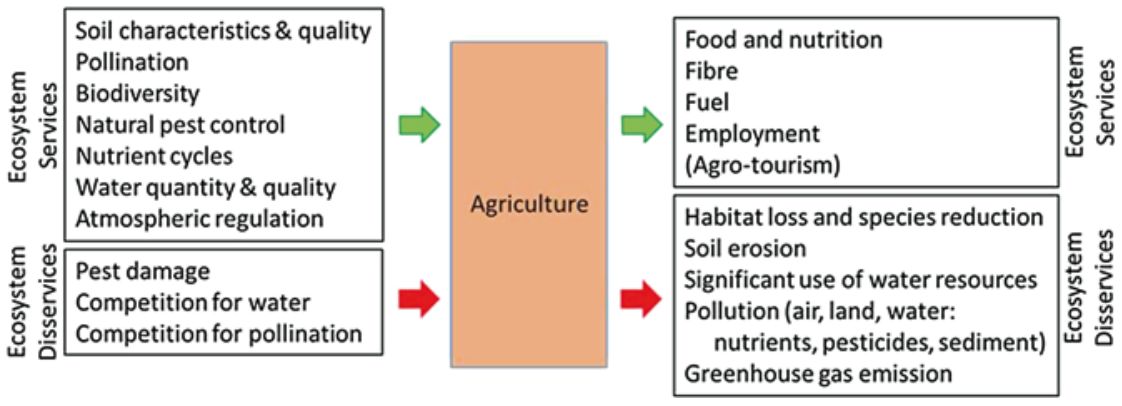

Fig. 24.1 The role of the agriculture ecosystem within ecosystem services

urbanisation increases, agriculture is becoming more and more important and the trade-off between the natural ecosystem services and provisioning ecosystem services from agriculture has to be clearly identified and managed with care (DeClerck et al. 2016; Gordon et al. 2010; Power 2010; Zhang et al. 2007). For example, in 2010, approximately 20 per cent of the world's population was employed in agriculture, but in certain countries, such as Bangladesh, this is significantly higher at 47.5 per cent (World Bank 2017). Changes in agricultural productivity can therefore have implications for both health and well-being.

Agricultural production in the coastal areas of Bangladesh faces many challenges including climatic and environmental change, water shortages and natural hazards (pest, diseases, floods) (FAO and MA 2013). Constraints to crop production are heavy soil consistency, low soil fertility, flooding in the monsoon season, poor soil structure causing delayed draining, high osmotic pressure causing a reduction in the ability of plants to absorb water and nutrients and cyclonic storm surges (see Chap. 18). In addition, soil salinisation is a major concern to farmers in these coastal regions (Baten et al. 2015). Salt naturally occurs in both soil and water; however the amount of salt present depends on both the soil characteristics and the hydrological settings. A high level of salt in the soil limits the ability of the plant to take up water and nutrients. Under normal conditions, the root cells have higher concentration of solutes than the soil water, and the difference allows a free and efficient movement of water into the plant root (i.e. osmotic effect). Increased salinity in the soil water lowers the rate of water transfer to the root; therefore, 
the plant needs to adapt osmotically by either accumulating salts or synthesising organic compounds such as sugars and organic acids (Hanson et al. 2006). These extra processes use energy, and thus the plant will be sub-optimally developed. In addition salts, like chloride, boron and sodium ions, can also cause toxicities for the plants when these are accumulated in the stems and leaves causing leaf-burns and twig-die-backs (Brown and Shelp 1997). Chloride, boron and sodium ions can be also absorbed through the leaves, thus irrigation water quality is even more important. Crop tolerance to salinity varies widely: some crops are very salt tolerant, but most crops are sensitive to salinity. This sensitivity also depends on the plant growth stage (i.e. germination, vegetative growth or reproductive growth). Many crops are more sensitive to salinity during the early vegetative stage (Mondal et al. 2015).

The accumulation of salts in the soils of agricultural regions occurs progressively when water evaporates from irrigated or flooded fields, leaving residual minerals. In Bangladesh, this problem is reduced during the annual monsoon which brings fresh rainwater to the system and displaces accumulated salts vertically down through the soil profile. As a result, monsoon season rice crop yields are reasonably good and adequate to support a subsistence level of farming in the coastal regions (see Chap. 23). However, evaporation in the dry season causes the salinity to re-develop each year (see Fig. 24.3, lower panel) which results in reduced soil fertility.

Irrigation in the dry season can counteract some of these problems, but the quality of the irrigation water quality is important. Many famers use groundwater or river water which can be partially contaminated with dissolved minerals, and these minerals add to the soil salinity when the applied water evaporates. Extreme events such as cyclones cause inundation of polders with sea water. This can take several years to flush out and typically requires two to three monsoon seasons to return the soils to their pre-inundation salinity levels (Rabbani et al. 2013). The salinity problem is further exacerbated by the move from rice production to brackish water shrimp and fish farming in coastal areas of Bangladesh. Although shrimp production is economically valuable to the owners, the deliberate inundation of polders with brackish or salt water contaminates soils and groundwater in adjacent areas and causes detrimental effects on both biodiversity and crop production of the region (Kartiki 2011). 
The aim of this chapter is to assess the effect of the present and future climate and irrigation practices on the crop growth potential in the southwest coastal zone of Bangladesh. Thus, Sect. 24.2 provides an overview of the crops and cropping systems in coastal Bangladesh, Sect. 24.3 introduces the methods, and Sect. 24.4 presents and discusses the results and implications.

\subsection{Current Conditions and Crops in the Study Area}

The agricultural sector of Bangladesh constitutes an important component of the national economy accounting for around 21 per cent of the national gross domestic product (GDP) (Clarke et al. 2015). The study area is located in the south-west coastal zone of Bangladesh and covers an area of approximately $19,000 \mathrm{~km}^{2}$ dominated, in 2010 , by agriculture ( 45 per cent), followed by natural vegetation (12 per cent), aquaculture (11 per cent), water ( 8 per cent) and wetland ( 8 per cent). This area represents some 30 per cent of the cultivated lands of Bangladesh (Karim et al. 1990; Lázár et al. 2015) and is mostly cultivated by subsistence farmers (Fig. 24.2). The warm humid climate of the region with relatively high annual rainfall (FAO CLIMWAT) provides farming communities excellent opportunities to grow crops on the silty clays of the delta (FAO and MA 2013).
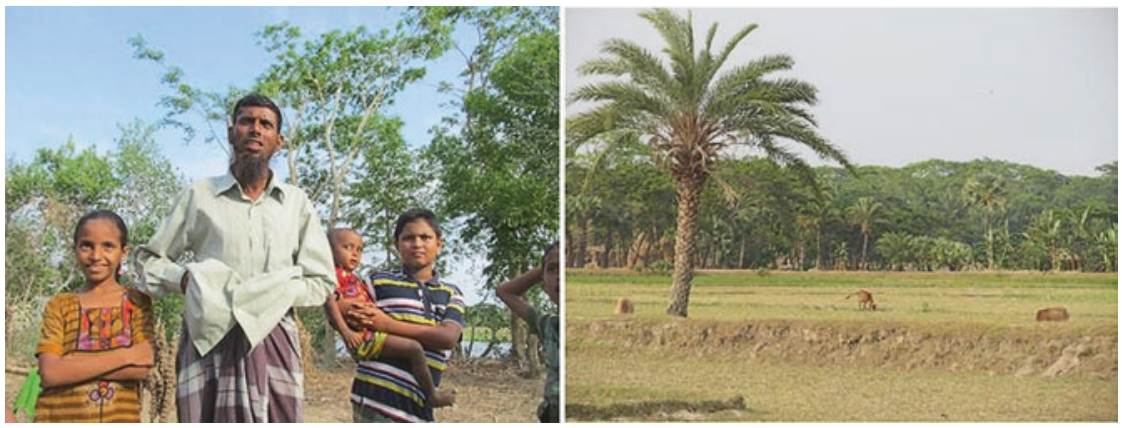

Fig. 24.2 Subsistence farmers (left) and agricultural landscape (right) of the south-west coastal region of Bangladesh (Photographs: Derek Clarke) 


\subsubsection{Crops, Seasonality and Irrigation}

The region experiences two contrasting seasons each year-wet (Kharif ) season, between June and October, when agriculture concentrates on wet foot rice production and the dry $(R a b i)$ season, between November and May, where water availability is reduced (Fig. 24.3). The agriculture calendar allows up to three crops per year during the monsoon (Kharif-1), post-monsoon (Kharif-2) and dry season (Rabi). Rice is the dominant crop, and there are three broad categories of rice cultivated

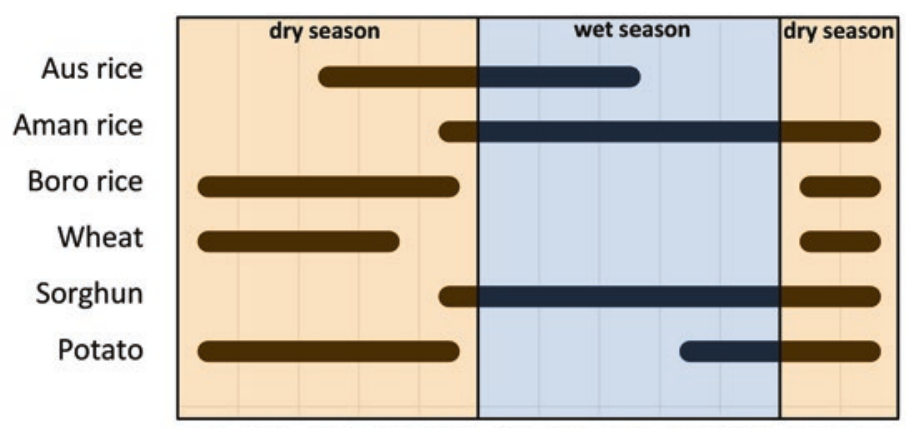

Jan Feb Mar Apr May Jun Jul Aug Sep Oct Nov Dec

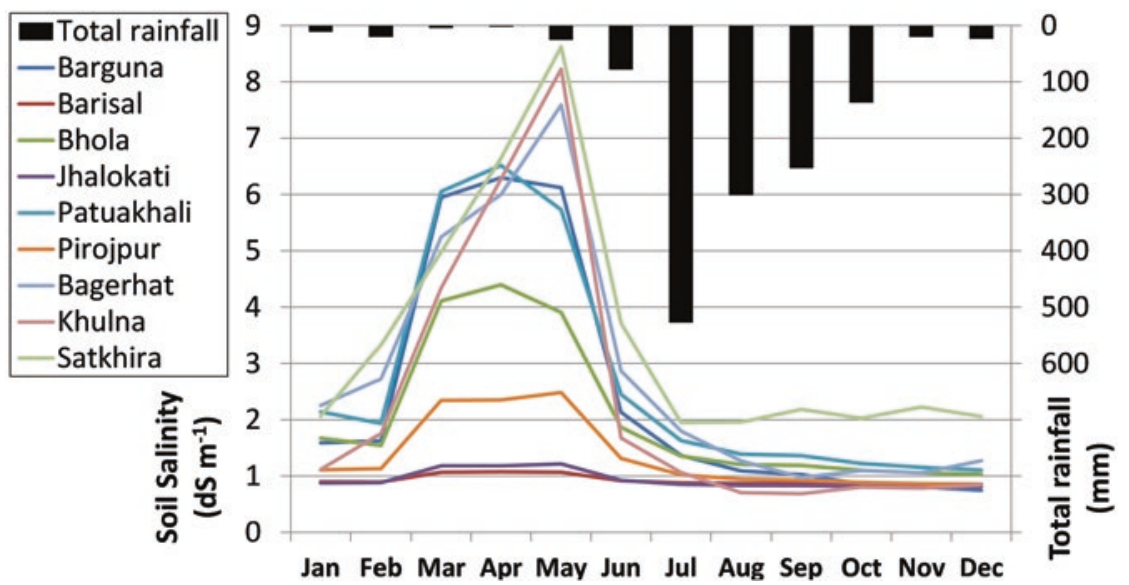

Fig. 24.3 (Upper) Simplified crop calendar adapted for the study area (based on FAO/WFP 2008); (lower) Rainfall distribution and soil salinity in southern Bangladesh (after Lázár et al. 2015) 
in different 'agriculture seasons': Aman rice (May to December), Boro (November to May) and Aus (March to August) (Murshid 2012; Banglapedia 2012). Aman rice is the most important staple food, and due to the monsoon rains, it requires minimal irrigation. Boro rice on the other hand requires irrigation during the dry winter period. Increasing soil salinity in the dry season has encouraged farmers to diversify production to include salt-tolerant crops such a mustard seed and watermelon (Ibrahim et al. 2009). The lack of irrigation water, however, prevents all-year-round agriculture in many places of the south-east part of the study area.

\subsubsection{Soil Quality in Coastal Areas}

The soils of the coastal lands in southern Bangladesh are relatively poor compared to other areas of Bangladesh, requiring the use of fertiliser (FRG 2012). The organic matter content is low to medium (1.0-3.4 per cent, wet oxidation method) with low nitrogen $(\mathrm{N})$ content $(0.091-0.18$ per cent, Kjeldahl method). The soil phosphorus (P) status is very low to low $\left(1.0-15.0 \mathrm{mg} / \mathrm{kg}, 0.5 \mathrm{M} \mathrm{NaHCO}_{3}\right.$ extractable), the potassium $(\mathrm{K})$ status is medium to optimum $\left(0.181-0.36 \mathrm{c} \mathrm{mol} / \mathrm{kg}, 1 \mathrm{M} \mathrm{NH}_{4} \mathrm{OAc}\right.$ extractable) and the sulphur $(\mathrm{S})$ status is also medium to optimum $(15.1-30.0 \mathrm{mg} / \mathrm{kg}$, $\mathrm{CaH}_{2} \mathrm{PO}_{4}$ extractable). Micronutrients especially the zinc $(\mathrm{Zn})$ status is low to medium (0.451-1.35 mg/kg, DTPA extractable), and the boron (B) status is medium to optimum $\left(0.31-0.60 \mathrm{mg} / \mathrm{kg}, \mathrm{CaCl}_{2}\right.$ extractable).

Many of these soils are classified as alkaline soils. In the Ganges tidal floodplain and the Young Meghna Estuarine Floodplains, 25 per cent of the agricultural land is highly saline (soil electrical conductivity (EC) above 12.0 deciSiemens per metre $(\mathrm{dS} / \mathrm{m}))$, and the remaining 75 per cent suffers from slight to moderate soil salinity (EC value 2.0-6.0 dS/m) (Ahsan 2010). The relationship between irrigation water salinity and soil salinity is complex and depends on the volumes of water used, the effectiveness of the monsoon rainfalls and water management practices such as land drainage. Mondal et al. (2015) describe series of experiments on the impacts of irrigation water quality on rice production. Salinity stress on rice crops starts if the irrigation water quality exceeds $3 \mathrm{dS} / \mathrm{m}$, and crop yields will fall by 80 per cent if the irrigation water quality is greater than $10 \mathrm{dS} / \mathrm{m}$. 


\subsubsection{Historical Changes in Crop Varieties}

Farmers are always willing to adopt new varieties of crops if they perceive the benefits. However, farmers in the coastal areas are generally more conservative and reluctant to use balanced doses of fertiliser application. With assistance from plant breeders and extension workers from the Bangladesh Department of Agricultural Extension (DAE), ${ }^{1}$ farmers have gradually moved from traditional low-yielding rice varieties and broadcast planting to higher-yielding varieties (HYV) and transplanted rice which, if kept well-watered and fertilised, can more than double production. In the 1990s, local crop varieties dominated the cropping patterns (e.g. broadcast Aman), but after 2000, the crop production shifted towards high-yielding and more resilient varieties (Fig. 24.4). At the same

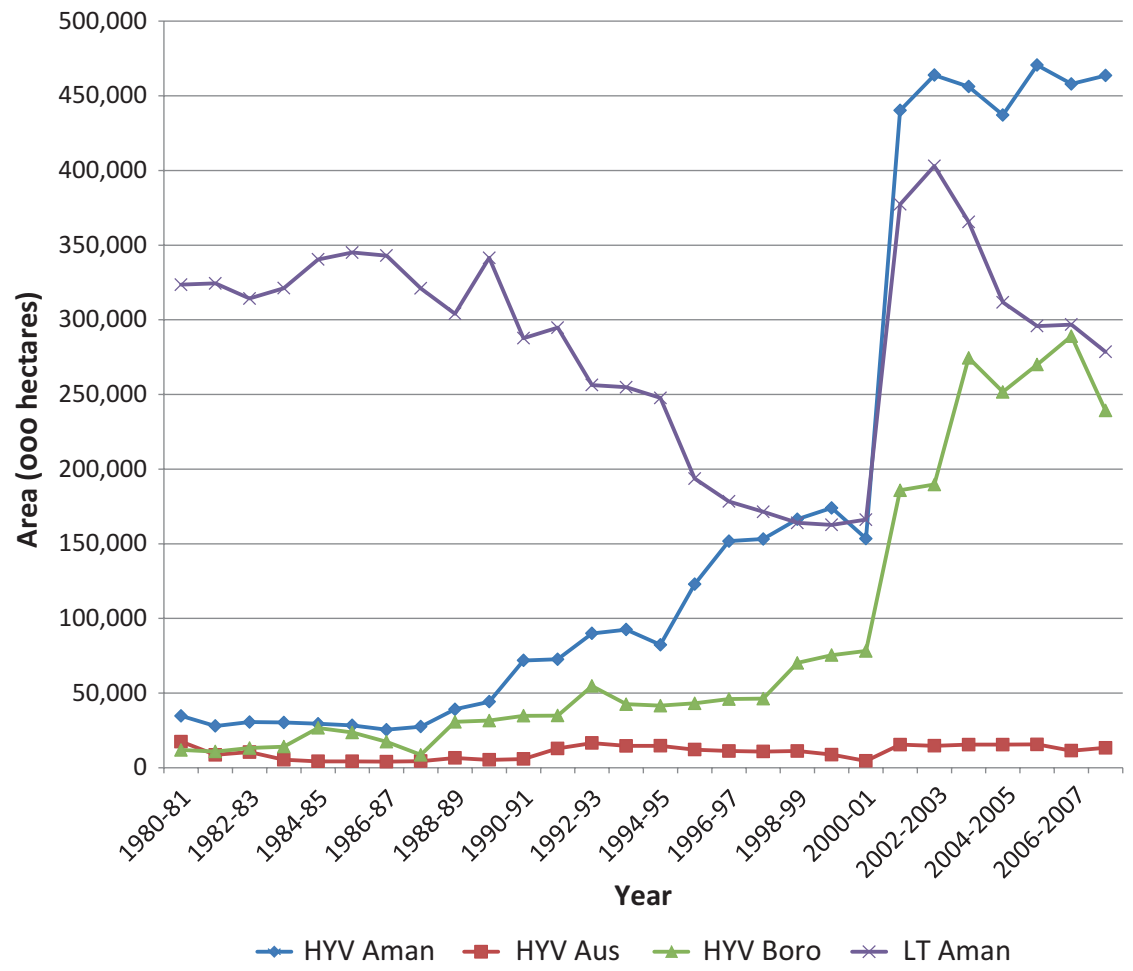

Fig. 24.4 Rice crop area (ha) grown in the Khulna region between 1980 and 2008 (Based on data from the Center for Environmental and Geographic Information) 

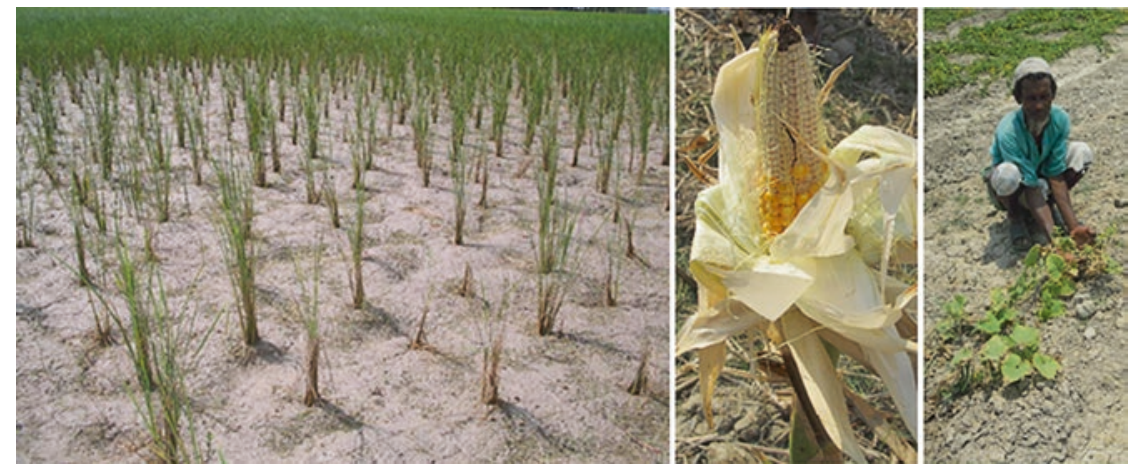

Fig. 24.5 Dry season salinity effects: (left) rice failing to germinate, (centre) maize yield reduction and (right) melon damaged by salinity and drought (Photographs: Derek Clarke)

time, diversity of the crops also increased (e.g. potato, wheat, chilli, etc.) thanks to the dissemination of modern technologies and knowledge by various agencies and Non-Governmental Organisations (NGOs).

However, despite these changes in the dry season, agriculture remains difficult and large areas of land are sometimes incapable of being used productively until the next monsoon rainfall dilutes the accumulated salts (Fig. 24.5). More salt-tolerant crop types and varieties, for example, mustard, chilli and rapeseed, have been adopted, but the more marginal areas continue to be constrained by soil conditions, high dry season soil salinity and lack of finance to invest in alternate crops.

\subsection{Estimating Changes in Climate and Soil Salinity on Agriculture}

Research on the dry season salinity problem was undertaken to investigate the climate variability within coastal Bangladesh, to determine whether inter-annual variability is more important than the longer-term climatic trends associated with future climate change, whilst also identifying the key salt mechanism and its likely relationship with reductions in agricultural yield. 


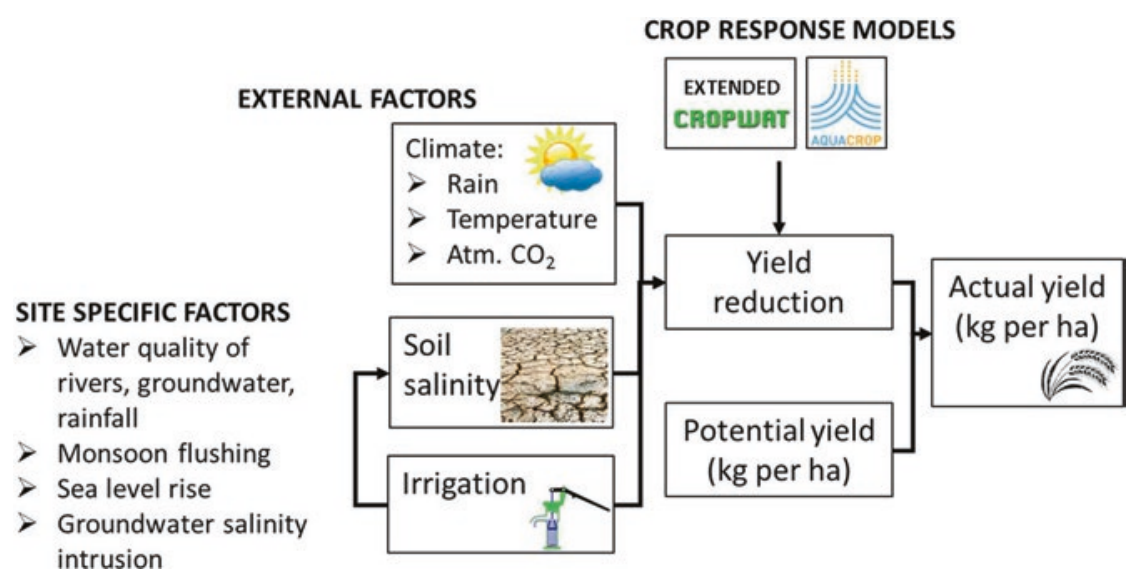

Fig. 24.6 Information used to model and evaluate future salinity and impacts on crop production

\subsubsection{Methodology}

The modelling-based assessment used both soil moisture and salt balance models (e.g. Andales et al. 2011; Clarke et al. 2015), run using future estimates of rainfall and climate factors that affect evaporation (Fig. 24.6). The soil moisture model is based on the FAO CROPWAT methodology which is a vertical water balance model (Clarke et al. 1998). This was extended by the authors to include a calculation of salt mass transfer through a typical irrigated farm. Salt inputs are from irrigation water from groundwater pumps or river channels at known salinity concentrations (Clarke et al. 2015). The extended CROPWAT model calculates the volume of water needed to irrigate crops in the dry season together with the mass of salt accumulated from minerals in the slightly salty irrigation water. The model calculates the soil leaching requirement and the volume of fresh rainwater to remove the salts in the monsoon season. The models require information on the crop types grown, their tolerances to water and salt stress and soil water storage characteristics. These were obtained from the FAO guidelines for crop evapotranspiration (Allen et al. 1998). The models are run at a daily time step using daily values of rainfall of the 1980-2100 period (HADRM3P climate model, UK Met Office, pers. 
comm, described in Chap. 11 and Caesar et al. 2015). Evapotranspiration was calculated using the Penman-Monteith equations for potential evapotranspiration using climatic data for Barisal obtained from the FAO CLIMWAT climatic database (CLIMWAT 2017). Estimates of future potential evapotranspiration were made using the baseline FAO CLIMWAT climate data set perturbed according to temperature increases proposed by Agrawala et al. (2003).

The model runs include calculations of the soil moisture deficit (SMD), ${ }^{2}$ the masses of salts accumulated in the soils in the dry season and the masses removed by leaching by fresh rainwater in the wet season over a typical one hectare field near Barisal. The overall aim was to calculate changes in and draw conclusions on the future seasonal and inter-annual variability of evaporative demands, the amount and schedule of irrigation required in the dry season for growing vegetables, as well as determining the accumulation of annual unleached salts and its effect on potential crop yields.

\subsubsection{Modelling Results}

\subsubsection{Timing and Length of the Monsoon Season}

Using the rainfall and calculated SMD in each year of the simulations, it is possible to determine the start and length of the monsoon season, that is, when the soil is sufficiently wet to grow main season Aman rice. This is shown in Fig. 21.7. Inter-annual (i.e. year to year) variability remains the dominant forcing in terms of dry season climate throughout the twentyfirst century, despite the long-term climate trends also present within the future climate (see Chap. 11). This variability is most evident within the changes to the length of the seasons, whereas changes to both the onset and magnitude exhibit smaller trends. The source of this variability is not yet fully understood, but research suggests a significant part is due to the monsoon circulation and its interconnection with both the El Niño-Southern Oscillation (ENSO) and Madden-Julian Oscillation (MJO-the largest element of the intra-seasonal variability in the tropical atmosphere).

The simulations indicate that the monsoon season is expected to shorten by two to three weeks, and the onset of the season will be four to five days later by the end of the twenty-first century. However, despite the 
reduced season length, the total annual rainfall is likely to remain the same or increase by five to ten per cent. This implies that the monsoon rainfall is expected to intensify by the end of the century. This shortening of the wet season, when combined with the year to year variability could result in some monsoon seasons being too short for a successful rice crop by the end of the twenty-first century (e.g. Fig. 24.7 upper-2055,
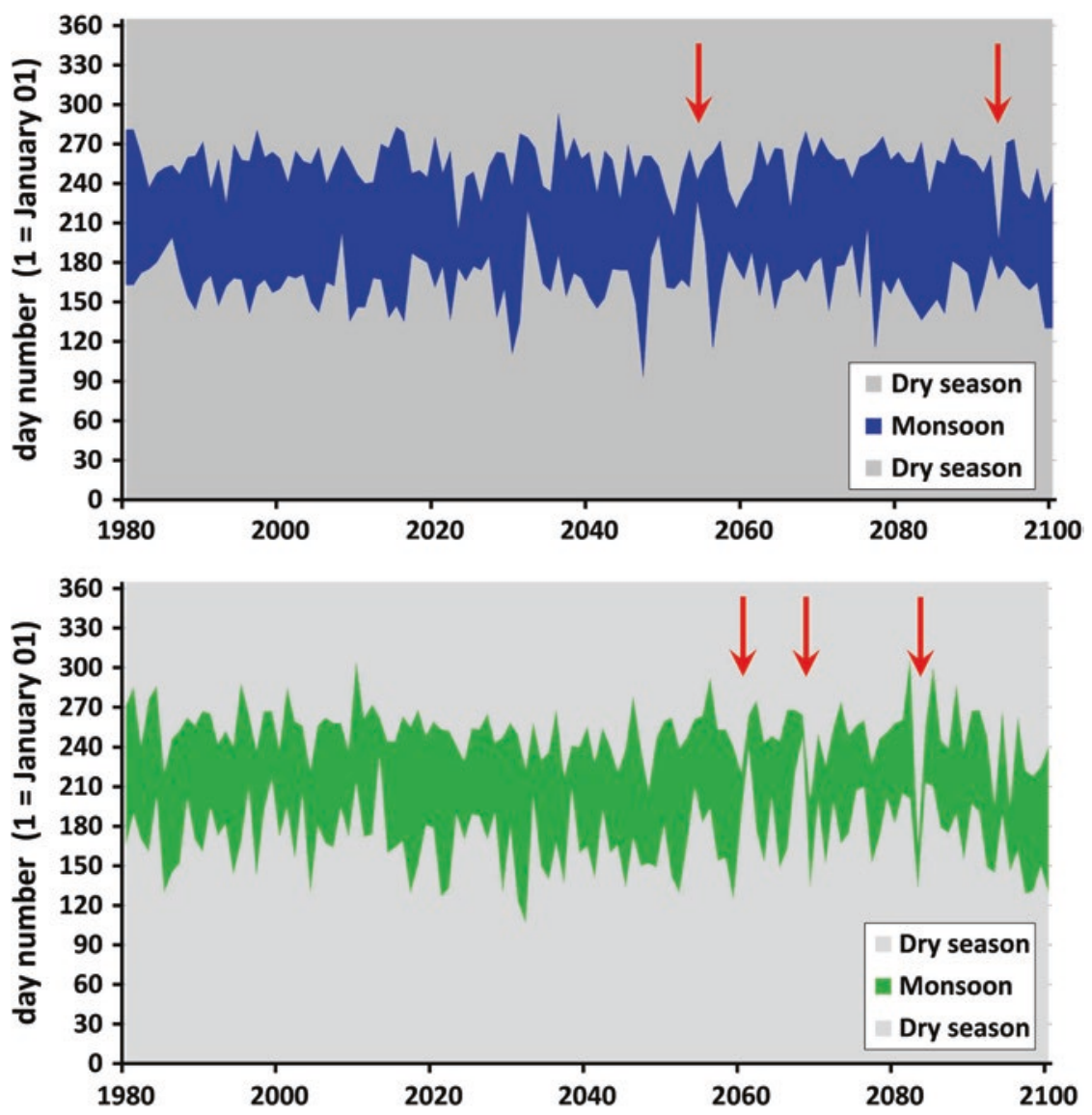

Fig. 24.7 (Upper) Calculated changes in the start and duration of the Monsoon based on rainfall duration (Q8 realisation of the HadRM3P regional climate model); (lower) Calculated changes in the start and duration of the Monsoon based on soil moisture deficit. 
2093; Fig. 24.7 lower-2061,2068,2083, as indicated by arrows). This phenomenon is also visible in other climate realisations (e.g. Q0 and Q16; see Chap. 11).

\subsubsection{Dry Season Water Requirements and Salinity Accumulation in Soils}

The dry season exhibits long-term climate forcing with the length of the season expected to increase by 14 days towards the end of the twenty-first century. This is due to the fact that higher temperatures will result in more evapotranspiration and a longer period when the soils are dry, requiring more initial rainfall to re-wet the soil at the start of the monsoon season. Potential evapotranspiration was found to be less variable year to year and tended to rise slightly with increasing temperature. The dry season is thus expected to become drier with the SMD increasing by $25 \mathrm{~mm}$ of soil water and, with the onset of the maximum SMD occurring four to five days earlier, an earlier onset of the dry season is suggested. However, dry season irrigation requirements will not increase because the growing period of crops will remain unchanged. Although higher temperatures increase potential evapotranspiration (by five to ten per cent), actual crop evapotranspiration is controlled more by soil moisture storage and irrigation water applied by farmers then by changes in temperature. It is the inter-annual variability of rainfall which will cause changes to both the amount and timing in the application of irrigation water.

Human water management as well as natural environmental changes both have impact on future soil salinity accumulation. If farmers use available groundwater or river water to irrigate in the dry season, the salt load in the irrigation water will be deposited in the soils when the water is evaporated or transpired by crops. Hence the soil salinity conditions will depend on a combination of human factors such as which crop to grow, crop salinity tolerance, irrigation or no irrigation and maintenance of drainage systems to remove leached salts.

Additional environmental factors also exist, such as duration of the dry season, salinity of the irrigation water used, shallow water table problems, magnitude of the next monsoon season and its ability to naturally leach salts 
out of the soil profile. Typical 'good' irrigation water may contain one to two parts per thousand (ppt) of minerals. Medium-quality water contains 4-6 ppt, and low-quality water may contain 8-12 ppt or higher. Simulations explored the effect of irrigation water quality on salt accumulation in the soil.

The extended CROPWAT model results show that at present (2015) in the Barisal region, if the dry season irrigation water contains less than 4 ppt salts, the monsoon rains in the following season will be able to flush these salts away (the amount of rain is higher than leaching required). However in drier years or if farmers use lower-quality irrigation water, the residual salts will start to accumulate to be carried over to the next dry growing season, worsening soil salinity and decreasing crop yields. The models were run into the future (to 2100) with a range of assumed values of irrigation water quality (Fig. 24.8). Irrigation water qualities of less than 4 ppt result in a small impact of salinity causing less than ten per cent reduction in expected crop yields of dry season vegetable crops. If the irrigation water quality in the dry season remains at $4 \mathrm{ppt}$, then the monsoon in the following season is able to flush away the accumulated salts in almost every year (there is one exception in this simulation in year 2070. Note that this simulation uses stochastic methods, so the date is not absolute).

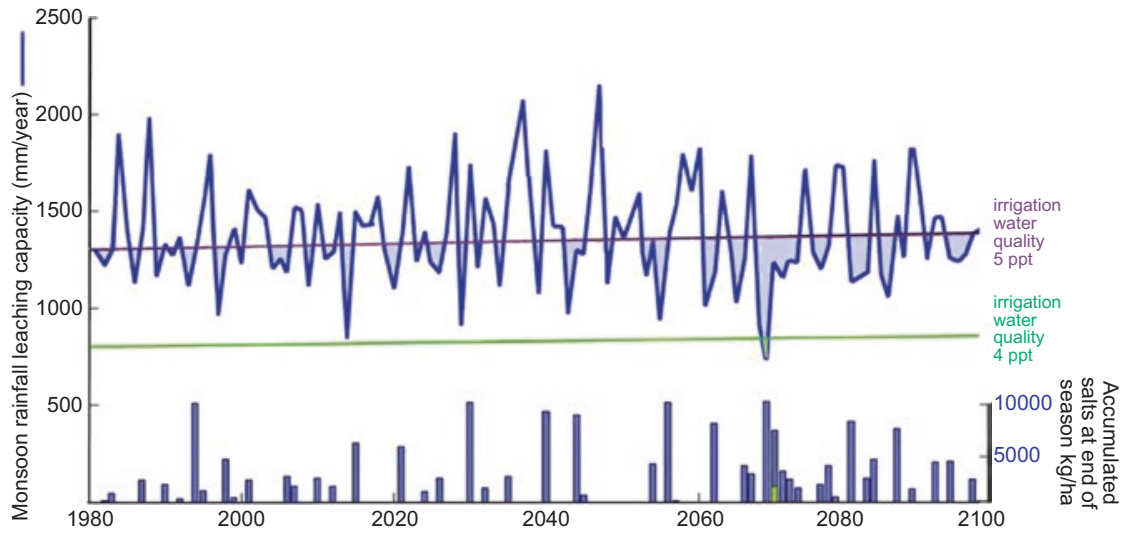

Fig. 24.8 Changes in the leaching capacity of the monsoon season rains compared with salts introduced by dry season irrigation with water qualities of $4 \mathrm{ppt}$ and 5 ppt dissolved mineral content 
If the regional water quality was to worsen (e.g. caused by various factors which might include sea-level rise, cyclones, use of lower-quality groundwater for irrigation), then irrigating crops results in the salts not being removed during the following monsoon season (see 5 ppt irrigation quality on Fig. 24.8) in 48 of the 120 years of the simulation. The residual salts are carried over to the next dry crop season with consequences for crop yields; in this case the anticipated crop yield loss due to salinity is 25 per cent. Note that this is a cumulative process, and, if this occurs in consecutive years, soil salinity levels increase over time and even lower potential crop yields are produced.

With the saline intrusion along river estuaries and into the shallow groundwater along the coast associated with anticipated sea-level rise (Kay et al. 2015; Bricheno et al. 2016), the decrease in the quality of irrigation water sources will be a significant factor determining future dry season agricultural productivity within the coastal zone. These findings align with the work of the World Bank (Dasgupta et al. 2014) which indicated that the coastal regions with close proximity to the coast and/ or major rivers are expected to see crop yields reduced by more than 50 per cent by the end of the twenty-first century. In this situation farmer's incomes will be reduced, livelihoods threatened and they will have to be more and more reliant on the main season rice as a subsistence crop.

\subsubsection{Temperature and Carbon Dioxide}

In addition to water and salinity stress, other effects on plants will develop due to anticipated climatic change. Crop response to changes in atmospheric carbon dioxide $\left(\mathrm{CO}_{2}\right)$ and temperature differs between crop types and individual varieties of these crops. Changes in $\mathrm{CO}_{2}$ concentrations will assist plant development and biomass accumulation. Parry et al. (2004) suggest that grain crop production will increase by between two to five per cent if atmospheric $\mathrm{CO}_{2}$ rises from the 2016 value of 400 parts per million (ppm) to $500 \mathrm{ppm}$, which is anticipated to occur in the 2040s.

Fig. 24.9 shows a possible trajectory of $\mathrm{CO}_{2}$ (SRES A1B scenarioKNMI 2016) and the calculated $\mathrm{CO}_{2}$ fertilisation (i.e. atmospheric fertigation) response factor. This crop growth response factor is not a direct a multiplier of yield, rather just one factor of many that influences the crop 


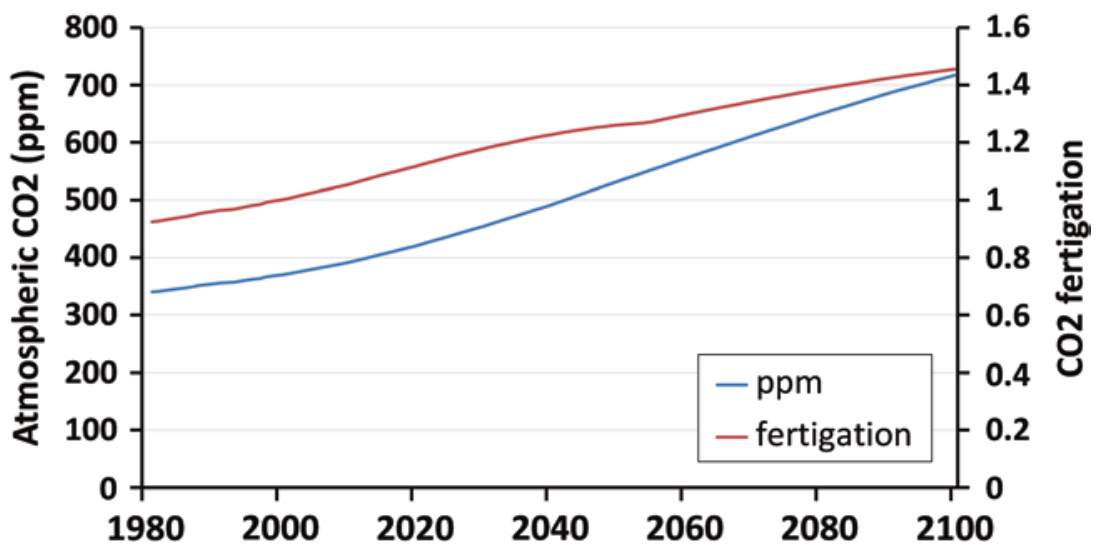

Fig. 24.9 Projected changes in carbon dioxide in the study area and changes in the crop fertigation

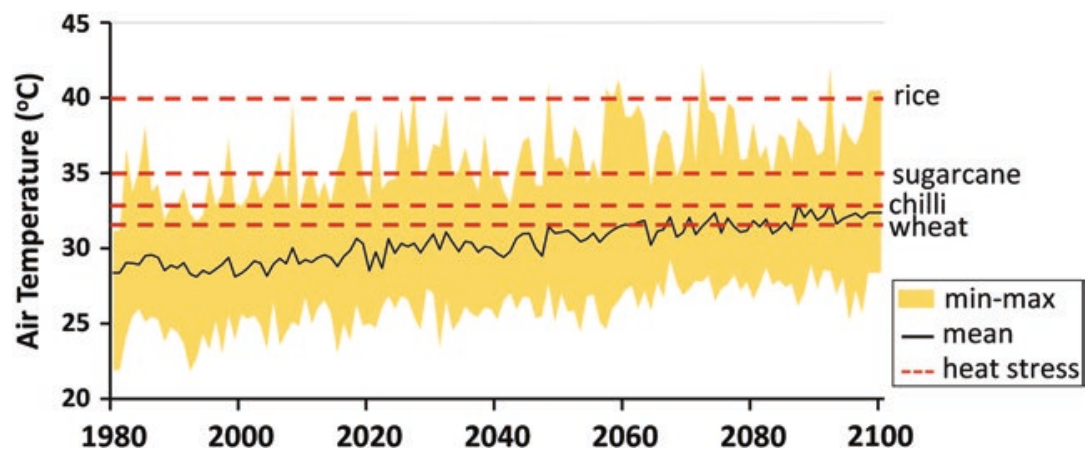

Fig. 24.10 Projected changes in air temperature in the study area compared with crop tolerance to heat stress

physiology. The overall crop yield is affected by numerous factors including crop type and variety, water availability, soil salinity, tolerance to heat, good farming practices and the appropriate use of adequate fertilisers on the poor soils.

Increased crop yields due to $\mathrm{CO}_{2}$ fertigation are likely to be counteracted by heat stress on plants as global temperatures increase (Sánchez et al. 2014; Peng et al. 2004). Figure 24.10 shows the projected changes in temperatures used in this study and the values which will cause the onset of reduced crop yields. Rice is not likely to be affected by heat 
limitations in the near future. However other key crops are already potentially constrained and this effect will increase as the twenty-first century progresses. This suggests that the staple rice crop will remain viable, but relatively recently adopted crops such as chilli may not be so successful and new non-rice crop types may have to be adopted in the future.

\subsection{Discussion}

Agriculture is the single most important provider of ecosystem services to the people of south-west Bangladesh. Monsoon rains supply adequate water to grow a main season rice crop. However, income from agriculture is currently constrained by the limited availability of good quality irrigation water in the dry season, access to markets and the cost of fertilisers. In Bangladesh, the market prices for rice are low so farmers have little or no surplus income to develop coping strategies. Compounding these problems is the fact that the coastal farming communities are also most at risk of flooding due to cyclones.

Farmers attempt to improve their incomes by growing dry season crops such as oil seeds and vegetables, but in coastal regions, dry season soil salinity severely limits crops production (see Chap. 28). The responses to these stressors by low-income farmers are limited, for example, localised irrigation with water of low quality or flooding some areas with brackish river water for aquaculture. These desperate actions, however, serve to increase the salt loading introduced to the fields, and a successful rice crop in the following wet season will depend on removal of accumulated salts. Therefore, although the development of soil salinity is an environmental process, soil salinisation is closely linked to farmers' behaviour and land use practices. This, in turn, not only reduces the agriculture productivity but also is closely associated with the decline in other ecosystem services associated with water regulation (coastal wetlands, mangroves, etc.).

These issues are exacerbated by projections of regional changes in sea levels, higher temperatures and reduced dry season river flows. Higher sea 
levels will increase mean water levels and the potential overtopping of polders by sea water (Kay et al. 2015), reducing the effectiveness of drainage systems to remove saline water to the sea. Higher temperatures will increase evaporation rates which will increase the need for irrigation in the dry season. Reduced river flows (see Chap. 13 and Whitehead et al. (2015)) mean that brackish water will penetrate further up river channels (Chap. 17 and Bricheno et al. (2016)), and when this water is used for dry season irrigation, this will accelerate the salt loading in the fields. Impacts on groundwater quality have not been fully quantified, but there are strong linkages between river water quality and groundwater salinity (Chap. 18 and Salehin et al. (2014)), so increased use of groundwater for agriculture may accelerate the deterioration of soil productivity due to soil salinity.

These findings reveal that both climate change, inter seasonal climate variability and saline intrusion are important drivers determining the productivity of dry season agriculture in the coastal regions of Bangladesh. There is a tipping point of water quality around $4 \mathrm{ppt}$ beyond which soil salinity development accelerates. In effect salinity is an impact resulting from the trade-offs between ecosystems system functioning, natural environmental change and human responses that lead in turn to trade-offs between provisioning and regulating ecosystems (see Chap. 2).

\section{Notes}

1. Agricultural extension workers provide knowledge to farmers on good management practices including eco-friendly, safe, climate resilient and sustainable methods and new crop varieties. In Bangladesh the extension system is run by the Department of Agricultural Extension http://www. dae.gov.bd/

2. Soil moisture deficit (SMD) is a measure of the dryness of the soil. SMD is defined as the amount of water (in $\mathrm{mm}$, the same units as rainfall) that is needed to return the soil to field capacity (close to saturation). A fully wet soil has an $\mathrm{SMD}=0 \mathrm{~mm}$, and a soil with $\mathrm{SMD}$ greater than approximately $80 \mathrm{~mm}$ will cause crop stress and start to reduce yields. 


\section{References}

Agrawala, S., T. Ota, A.U. Ahmed, J. Smith, and M.V. Aalst. 2003. Development and climate change in Bangladesh: Focus on coastal flooding and the Sundarbans. Paris: Organisation for Economic Co-operation and Development. www. oecd.org/env/cc/21055658.pdf. Accessed 28 June 2016.

Ahsan, D.A. 2010. Saline Soils of Bangladesh. Soil Resource Development Institute, Ministry of Agriculture. http://srdi.portal.gov.bd/sites/default/files/files/srdi. portal.gov.bd/publications/bc598e7a_df21_49ee_882e_0302c974015f/ Soil\%20salinity\%20report-Nov\%202010.pdf.

Allen, R.G., L.S. Pereira, D. Raes, and M. Smith. 1998. Crop evapotranspiration - Guidelines for computing crop water requirements. FAO Irrigation and drainage paper 56. Rome: Food and Agriculture Organization of the United Nations (FAO). http://www.fao.org/docrep/x0490e/x0490e00.htm. Accessed 6 Mar 2017.

Andales, A.A., J.L. Chavez, and T.A. Bauder. 2011. Irrigation scheduling: The water balance approach. Colorado: Extension, Colorado State University. http://www.etgage.com/04707.html. Accessed 6 Mar 2017.

Banglapedia. 2012. National Encyclopedia of Bangladesh, 2nd ed. Asiatic Society of Bangladesh. www.http://en.banglapedia.org/

Baten, M., L. Seal, and K. Lisa. 2015. Salinity intrusion in interior coast of Bangladesh: Challenges to agriculture in South-Central Coastal Zone. American Journal of Climate Change 4: 248-262. https://doi.org/10.4236/ ajcc.2015.4302.

Bricheno, L.M., J. Wolf, and S. Islam. 2016. Tidal intrusion within a mega delta: An unstructured grid modelling approach. Estuarine Coastal and Shelf Science 182: 12-26. https://doi.org/10.1016/j.ecss.2016.09.014.

Brown, P.H., and B.J. Shelp. 1997. Boron mobility in plants. Plant and Soil 193 (1): 85-101. https://doi.org/10.1023/A:1004211925160.

Caesar, J., T. Janes, A. Lindsay, and B. Bhaskaran. 2015. Temperature and precipitation projections over Bangladesh and the upstream Ganges, Brahmaputra and Meghna systems. Environmental Science-Processes and Impacts 17 (6): 1047-1056. https://doi.org/10.1039/c4em00650j.

Clarke, D., M. Smith, and K. El-Askari. 1998. New software for crop water requirements and irrigation scheduling. Irrigation and Drainage 47 (2): 45-58.

Clarke, D., S. Williams, M. Jahiruddin, K. Parks, and M. Salehin. 2015. Projections of on-farm salinity in coastal Bangladesh. Environmental ScienceProcesses and Impacts 17 (6): 1127-1136. https://doi.org/10.1039/c4em00682h. 
CLIMWAT. 2017. Databases and software. Food and Agriculture Organisation of the United Nations (FAO). http://www.fao.org/land-water/databases-andsoftware/climwat-for-cropwat/en/. Accessed 11 May 2017.

Dasgupta, S., F.A. Kamal, Z.H. Khan, S. Choudhury, and A. Nishat. 2014. River salinity and climate change: Evidence from coastal Bangladesh. Policy working paper series 6817. Washington, DC: The World Bank. http://documents. worldbank.org/curated/en/522091468209055387/River-salinity-andclimate-change-evidence-from-coastal-Bangladesh. Accessed 11 Apr 2014.

DeClerck, F.A.J., S.K. Jones, S. Attwood, D. Bossio, E. Girvetz, B. Chaplin-Kramer, E. Enfors, A.K. Fremier, L.J. Gordon, F. Kizito, I. Lopez Noriega, N. Matthews, M. McCartney, M. Meacham, A. Noble, M. Quintero, R. Remans, R. Soppe, L. Willemen, S.L.R. Wood, and W. Zhang. 2016. Agricultural ecosystems and their services: the vanguard of sustainability? Current Opinion in Environmental Sustainability 23: 92-99. https://doi.org/10.1016/j.cosust.2016.11.016.

FAO, and MA. 2013. Master plan for agricultural development in the Southern Region of Bangladesh. Food and Agriculture Organization of the United Nations (FAO) and Government of the People's Republic of Bangladesh, Ministry of Agriculture (MA).

FAO/WFP. 2008. FAO/WFP crop and food supply assessment mision to Bangladesh. Annex 2. Rome: Food and Agriculture Organisation of the United Nations (FAO). http://www.fao.org/docrep/011/ai472e/ai472e00.htm\#29. Accessed 11 May 2017.

FRG. 2012. Fertilizer recommendation guide-2012. Soils publication no. 32 . Dhaka: Bangladesh Agricultural Research Council (BARC). https://archive. org/details/FertilizerRecommendationGuide2012_201509. Accessed 6 Mar 2017.

Gordon, L.J., C.M. Finlayson, and M. Falkenmark. 2010. Managing water in agriculture for food production and other ecosystem services. Agricultural Water Management 97 (4): 512-519. https://doi.org/10.1016/j.agwat.2009.03.017.

Hanson, B.R., S.R. Grattan, and A. Fulton. 2006. Agricultural salinity and drainage. Division of Agriculture and Natural Resources Publication 3375. Davis: University of California. http://hos.ufl.edu/sites/default/files/faculty/ gdliu/HansonGrattan2006_0.pdf. Accessed 21 Mar 2017.

Ibrahim, M., A.A. Hassan, I. Huque, and A.U. Ahmed. 2009. Adaptive crop agriculture including innovative farming practices in the coastal zone of Bangladesh. Technical report. Dhaka: Center for Environmental and Geographic Information Services (CEGIS). https://www.researchgate.net/ publication/271210558_Adaptive_Crop_Agriculture_Including Innovative_Farming_Practices_in_the_Coastal_Zone_of_Bangladesh 
Karim, Z., S.G. Hussain, and M. Ahmed. 1990. Salinity problems and crop intensification in the coastal regions of Bangladesh. Soils publication no. 33 . Dhaka: Bangladesh Agricultural Research Council (BARC).

Kartiki, K. 2011. Climate change and migration: a case study from rural Bangladesh. Gender and Development 19 (1): 23-38. https://doi.org/10.108 0/13552074.2011.554017.

Kay, S., J. Caesar, J. Wolf, L. Bricheno, R.J. Nicholls, A.K.M.S. Islam, A. Haque, A. Pardaens, and J.A. Lowe. 2015. Modelling the increased frequency of extreme sea levels in the Ganges-Brahmaputra-Meghna delta due to sea level rise and other effects of climate change. Environmental Science-Processes and Impacts 17 (7): 1311-1322. https://doi.org/10.1039/c4em00683f.

KNMI. 2016. $\mathrm{CO}_{2}$ Time Series Data. Royal Netherlands Meteorological Institute (KNMI) Climate Explorer. http://climexp.knmi.nl/getindices. cgi?WMO=CDIACData/A1B\&STATION=A1B\&TYPE=i\&id=someone@ somewhere\&NPERYEAR=1. Accessed 11 May 2017.

Lázár, A.N., D. Clarke, H. Adams, A.R. Akanda, S. Szabo, R.J. Nicholls, Z. Matthews, D. Begum, A.F.M. Saleh, M.A. Abedin, A. Payo, P.K. Streatfield, C. Hutton, M.S. Mondal, and A.Z.M. Moslehuddin. 2015. Agricultural livelihoods in coastal Bangladesh under climate and environmental change A model framework. Environmental Science-Processes and Impacts 17 (6): 1018-1031. https://doi.org/10.1039/c4em00600c.

Mondal, M.S., A.F.M. Saleh, M.A. Razzaque Akanda, S.K. Biswas, A.Z. Md, S. Zaman Moslehuddin, A.N. Lazar, and D. Clarke. 2015. Simulating yield response of rice to salinity stress with the AquaCrop model. Environmental Science: Processes and Impacts 17 (6): 1118-1126. https://doi.org/10.1039/ C5EM00095E Licence 10.1039/C5EM00095E.

Murshid, S.M. 2012. Impact of sea level rise on agriculture using groundwater in Bangladesh. MSc thesis CoMEM programme, University of Southampton. https://repository.tudelft.nl/islandora/object/uuid:e484b9b8-e1d1-40b199ee-5c7a274ef500/?collection=research. Accessed 22 May 2017.

Parry, M.L., C. Rosenzweig, A. Iglesias, M. Livermore, and G. Fischer. 2004. Effects of climate change on global food production under SRES emissions and socio-economic scenarios. Global Environmental Change-Human and Policy Dimensions 14 (1): 53-67. https://doi.org/10.1016/j.gloenvcha.2003.10.008.

Peng, S., J. Huang, J.E. Sheehy, R.C. Laza, R.M. Visperas, X. Zhong, G.S. Centeno, G.S. Khush, and K.G. Cassman. 2004. Rice yields decline with higher night temperature from global warming. Proceedings of the National Academy of Sciences of the United States of America 101 (27): 9971-9975. https://doi.org/10.1073/pnas.0403720101. 
Power, A.G. 2010. Ecosystem services and agriculture: Tradeoffs and synergies. Philosophical Transactions of the Royal Society B: Biological Sciences 365 (1554): 2959. Licence. https://doi.org/10.1098/rstb.2010.0143.

Rabbani, G., A. Rahman, and K. Mainuddin. 2013. Salinity-induced loss and damage to farming households in coastal Bangladesh. International Journal of GlobalWarming5(4):400-415.https://doi.org/10.1504/IJGW.2013.057284. Salehin, M., M.S. Mondal, D. Clarke, A. Lazar, M. Chowdhury, and S. Nowreen. 2014. Spatial variation in soil salinity in relation to hydro-climatic factors in southwest coastal Bangladesh. Deltas in times of climate change II, September 24-26, Rotterdam.

Sánchez, B., A. Rasmussen, and J.R. Porter. 2014. Temperatures and the growth and development of maize and rice: A review. Global Change Biology 20 (2): 408-417. https://doi.org/10.1111/gcb.12389.

Whitehead, P.G., E. Barbour, M.N. Futter, S. Sarkar, H. Rodda, J. Caesar, D. Butterfield, L. Jin, R. Sinha, R. Nicholls, and M. Salehin. 2015. Impacts of climate change and socio-economic scenarios on flow and water quality of the Ganges, Brahmaputra and Meghna (GBM) river systems: Low flow and flood statistics. Environmental Science-Processes and Impacts 17 (6): 1057-1069. https://doi.org/10.1039/c4em00619d.

World Bank. 2017. Employment in Agriculture. World Bank Open Data. http:// data.worldbank.org/indicator/SL.AGR.EMPL.ZS. Accessed 9 Feb 2017.

Zhang, Wei, Taylor H. Ricketts, Claire Kremen, Karen Carney, and Scott M. Swinton. 2007. Ecosystem Services and Dis-services to Agriculture. Ecological Economics 64 (2): 253-260. https://doi.org/10.1016/j.ecolecon.2007.02.024.

Open Access This chapter is licensed under the terms of the Creative Commons Attribution 4.0 International License (http://creativecommons.org/licenses/ by/4.0/), which permits use, sharing, adaptation, distribution and reproduction in any medium or format, as long as you give appropriate credit to the original author(s) and the source, provide a link to the Creative Commons license and indicate if changes were made.

The images or other third party material in this chapter are included in the chapter's Creative Commons license, unless indicated otherwise in a credit line to the material. If material is not included in the chapter's Creative Commons license and your intended use is not permitted by statutory regulation or exceeds the permitted use, you will need to obtain permission directly from the copyright holder.

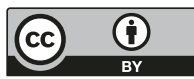

